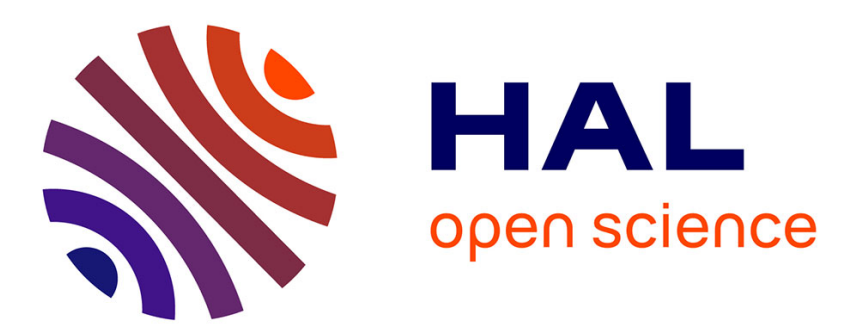

\title{
Modeling of strain rate effect on the pseudoelastic behavior of NiTi SMA using a simple thermomechanical coupling model
}

\author{
Ons Ammar, Lamine Dieng, Nader Haddar
}

\section{- To cite this version:}

Ons Ammar, Lamine Dieng, Nader Haddar. Modeling of strain rate effect on the pseudoelastic behavior of NiTi SMA using a simple thermomechanical coupling model. Mechanics of Materials, 2018, 124, pp. 7-17. 10.1016/j.mechmat.2018.05.004 . hal-03244602

\author{
HAL Id: hal-03244602 \\ https://hal.science/hal-03244602
}

Submitted on 1 Jun 2021

HAL is a multi-disciplinary open access archive for the deposit and dissemination of scientific research documents, whether they are published or not. The documents may come from teaching and research institutions in France or abroad, or from public or private research centers.
L'archive ouverte pluridisciplinaire HAL, est destinée au dépôt et à la diffusion de documents scientifiques de niveau recherche, publiés ou non, émanant des établissements d'enseignement et de recherche français ou étrangers, des laboratoires publics ou privés. 


\title{
Modeling of strain rate effect on the pseudoelastic behavior of NiTi SMA using a simple thermomechanical coupling model
}

\author{
Ons AMMAR ${ }^{\mathrm{a}}$, Nader HADDAR ${ }^{\mathrm{a}}$, Lamine DIENG ${ }^{\mathrm{b}}$ \\ ${ }^{a}$ Laboratoire de Génie des Matériaux et Environnement, ENIS, B.P.W.1173,3038 Université de Sfax, TUNISIA \\ b IFSTTAR, MAST, Route de Bouaye - CS 4 - 44341 Bouguenais Cedex - FRANCE
}

\begin{abstract}
:
NiTi SMA represents a popular group of metals with interesting properties like pseudoelasticity and a high energy dissipative capacity. Indeed, NiTi alloys, presents an interesting damping capacity due to solid-solid phase transformation. Such characteristics allow them to be used in many civil engineering fields mainly as actuators and damping devices. However, because of their complex behavior, the design process of these applications seems to be complicated and consequently, needs to build accuracy numerical models. One of these already existing models is the micromechanical Likhachev model. It seems to be very attractive thanks to its general formulation, numerical efficiency and model parameters relatively easy to determine. This paper concerns the numerical simulation of the pseudoelasticity behavior of NiTi wires dedicated to the application of damping devices, at different stress and strain rates. A thermomechanical coupling is introduced in the Likhachev formulation in order to simulate the thermomechanical behavior of NiTi under strain control. In this paper the model is adapted to a strain-controlled formulation, and 1D simulation is achieved using FORTRAN code. Parameters model are identified thanks to SiDoLo software and the corresponding results are presented and discussed. A good agreement with experimental data is found for the two formulations.
\end{abstract}

Key words: NiTi wires, damping device, strain-controlled, thermomechanical coupling formulation, Likhachev model, strain rate effect.

\section{Introduction:}

The micromechanical approach consists in subdividing a REV (Representative Elementary Volume) of material into a finite number of regions governed by a series of constitutive equations. The global (or macroscopic) behavior is then determined by 
calculating the average strain of each region. In the general case, models based on micromechanical approaches can also be classified as fundamental because they use a series of intrinsic microstructural parameters that can be difficult to measure during experimental tests [1] and so the experimental characterization of material constants should become very laborious. In addition, such models are allowed to describe and to explain several physical phenomena that occur during the martensitic transformation. The Likhachev's structural_analytical [2] model represents a good example of micromechanical modeling. The choice of Likhachev's model was motivated by its general formulation, numerical efficiency and easiness of characterization. Indeed, such model is able to simulate all the well-known shape memory-related behaviors such as pseudoelasticity, the shape memory effect and the two-way memory, as well as the other peculiarities of these materials like plastic microdeformations, stress generation when the alloy is restrained during heating, etc. The Likhachev Model (LM) material constants are relatively easy to characterize using common equipment (differential scanning calorimetry (DSC), tensile testing machine...) and these constants have a physical meaning and few calibrating parameters are introduced. Indeed, the structure-analytical theory proposed by Likhachev, is particularly attractive because it is physically grounded and able to deal with tensor stress and strain states. Unfortunately, its stress-controlled formulation has hindered its implementation in displacement based finite element programs. Among the great numbers of investigations, very few studies concern the adaptation of the Likhachev formulation to a strain-controlled formulation. The response of a SMA wire actuator controlled by direct Joule heating have been simulated by [3] using the commercial finite element software package, ANSYS. In fact, the 1D stress-controlled Likhachev constitutive equation has been adapted to be strain-controlled introducing an iterative algorithm. The same authors have been then introduced the $3 \mathrm{D}$ strain-controlled formulation based on an iterative algorithm and a proportional controller [4]. The resulting model was implemented in ANSYS and a simple finite element analysis was carried out. However, pseudoelasticity as well as the effect of rates on the hysteresis response under tensile loading have not been investigated.

The aim of this work is to propose a strain-controlled LM formulation and to study the effectiveness of the proposed thermomechanical coupling model to simulate the thermomechanical pseudoelastic response of NiTi wires under uniaxial tensile loads. The capability of this model to take into account the effect of stress and strain rates is evaluated. First, a brief review of stress-controlled 1D formulation of Likhachev's model and the adaptation of the equations to the strain-controlled formulation are presented. Then, results of 
simulation under the two formulations are shown and discussed. Finally, the numerical stressstrain curves at different stress/strain rates are presented and discussed.

\section{Likhachev's micromechanical model: 1D formulation}

The model's goal is to predict the macroscopic strain rate $\left(\dot{\varepsilon}_{t o t}\right)$ when a thermomechanical loads (stress rate $\dot{\sigma}$ and temperature rate $\dot{T}$ ) are applied. The macroscopic strain rate is decomposed into elastic strain $\left(\dot{\varepsilon}_{e l}\right)$ and transformation strain rates $\left(\dot{\varepsilon}_{t r}\right)$ as follows:

$$
\dot{\varepsilon}_{t o t}=\dot{\varepsilon}_{e l}+\dot{\varepsilon}_{t r}
$$

It is worth to notice that thermal expansion is not considered here because it is negligible compared to the other contributions.

The description of the elastic contribution is straightforward when using a mixing rule where the weighting parameter is the global volume of Martensite ' $\Phi_{M}$ ' in the entire volume of the material $\left(\Phi_{A}+\Phi_{M}=1\right)$

$$
\dot{\varepsilon}_{e l}=\left(\frac{1-\Phi_{M}}{E_{A}}+\frac{\Phi_{M}}{E_{M}}\right) \dot{\sigma}+\left(\frac{1}{E_{M}}-\frac{1}{E_{A}}\right) \dot{\Phi}_{M} \sigma
$$

where $\mathrm{E}_{\mathrm{A}}, \Phi_{\mathrm{A}}, \mathrm{E}_{\mathrm{M}}, \Phi_{\mathrm{M}}$ are the Young's Modulus and the global proportion of austenite and martensite, respectively.

For the calculation of the phase transformation strain rate, the elementary material volume is divided into a series of smaller volumes called 'regions'. Each region occupies the same volume. The number of regions is defined as ' $\mathrm{N}$ ' throughout this paper.

Knowing that each region has its own orientation with respect to the global frame , the phase transformation of the $\mathrm{n}^{\text {th }}$ region of SMA wire element is oriented along a single direction defined by the orientation angle ' $\theta_{n}$ ' (Fig.1). Consequently, the phase transformation strain rate in each region $\left(\dot{\varepsilon}_{t r, n}\right)$ is calculated as a product of the maximum intrinsic transformation " $\varepsilon_{\max }$ ' and the corresponding volume fraction of the martensite inside the $\mathrm{n}^{\text {th }}$ region ' $\dot{\phi}_{n}$ ':

$$
\dot{\varepsilon}_{t r, n}=\dot{\phi}_{n} \varepsilon_{\max }
$$

The macroscopic phase transformation strain rate $\left(\dot{\varepsilon}_{t r}\right)$ is calculated using the phase transformation strain rate of each region and its orientation: 


$$
\dot{\varepsilon}_{t r}=\frac{1}{N} \sum_{n=1}^{N} \dot{\phi}_{n} \varepsilon_{\max } \cos \left(\theta_{n}\right)
$$

Referring to Bhattacharya and Kohn [5], Epsilon Max ' $\varepsilon_{\max }$ ' represents in fact a vector of "k" stress free strains or transformation strains associated with martensite variants. It may be calculated from the lattice parameters of the austenite and the martensite. It is assumed that this parameter is identical for each region. ' $\varepsilon_{\max }$ ' is between 3 and $10.5 \%$ in the case of a NiTi crystal, depending on the applied stress. It was identified for each case using the parameter identification software "SiDoLo" [6]. $\phi^{n}$ represents the volume fraction of martensite in the $\mathrm{n}^{\text {th }}$ region compared to the initial volume of specimen $\left(\phi^{n}=\frac{\text { Volume Martensite region ' }^{\prime}{ }^{\prime}}{\text { initial Volume of region }}\right)$

where $\phi^{n}$ is between $\phi_{\min }$ and $\phi_{\max }$ which represent respectively, the minimum and the maximum fraction of martensite in the single region.

Similarly, the global (macroscopic) volume fraction of the Martensite ' $\Phi_{M}{ }^{\prime}$ is calculated by averaging the total of $\phi_{n}$ values as follows:

$$
\dot{\Phi}_{M}=\frac{1}{N} \sum_{n=1}^{N} \dot{\phi}_{n}
$$

The effective temperature ' $T_{n}^{*}$ represents one of the key features of the Likhachev model indicating whether the phase transformation is induced by mechanical or thermal loading. According to the Clausius-Clapeyron relation, the effective temperature rate in each region is a scalar value having for expression:

$$
\dot{T}_{n}^{*}=\dot{T}-\frac{\cos \left(\theta_{n}\right) \dot{\sigma}}{\beta}
$$

where ' $\dot{T}$ ' is the wire's temperature rate and ' $\beta$ ' is a parameter depending on the applied stress rate. Therefore, for the same loading given by a wire temperature ' $T$ ' and stress ' $\sigma$ ', each region will have different equivalent temperatures due to its different orientation ' $\theta_{n}$ '.

Knowing the effective temperature of each region, it is now possible to link these values to the proportions of martensite in each region through the transformation kinetic rule as graphically illustrated in Fig.2.

$\phi^{n}$ is written as follows: 


$$
\begin{aligned}
\dot{\phi}_{n} & =\frac{\dot{T}_{n}^{*}}{\left(M_{f}-M_{s}\right)} \cdot H\left[-\dot{T}_{n}^{*}\right] \cdot H\left[1-\Phi_{M}\right] \cdot H\left[\phi_{\max }-\phi_{n}\right] \cdot H\left[M_{s}-\dot{T}_{n}^{*}-\phi_{n}\left(M_{s}-M_{f}\right)\right] \\
& +\frac{\dot{T}_{n}^{*}}{\left(A_{s}-A_{f}\right)} \cdot H\left[\dot{T}_{n}^{*}\right] \cdot H\left[\Phi_{M}\right] \cdot H\left[\phi_{n}-\phi_{\min }\right] \cdot H\left[-A_{f}+\dot{T}_{n}^{*}+\phi_{n}\left(A_{f}-A_{s}\right)\right]
\end{aligned}
$$

This equation is the sum of two terms. As describe in [7] Each term is a product of five others terms: an amplitude $\left(\frac{\dot{T}_{n}^{*}}{M_{f}-M_{s}}, \frac{\dot{T}_{n}^{*}}{A_{s}-A_{f}}\right)$ and four Heaviside functions. The first contribution refers to a cooling in the direction of effective temperature while the second corresponds to the heating. A cooling suggests that $\dot{T}_{n}^{*}$ should be $<0$. The first two Heaviside functions $\left(\mathrm{H}\left[-\dot{T}_{n}^{*}\right]\right.$ and $\left.\mathrm{H}\left[\dot{T}_{n}^{*}\right]\right)$ indicate the direction of the transformation depending on whether the material is cooled or heated, according to the effective temperature. The next functions $\left(\mathrm{H}\left[1-\Phi_{M}\right]\right.$ and $\left.\mathrm{H}\left[\Phi_{M}\right]\right)$ mark out the total amount of volume fraction of martensite present in the specimen. In addition, the following Heaviside functions mark out the volume fraction of the Martensite within each region, this proportion cannot be higher than $\phi_{\max }\left(\mathrm{H}\left[\phi_{\max }-\phi_{n}\right]\right)$ or lower than $\phi_{\min }\left(\mathrm{H}\left[\phi_{n}-\phi_{\min }\right]\right)$. Finally, the remaining Heaviside functions $\left(H\left[M_{s}-\dot{T}_{n}^{*}-\phi_{n}\left(M_{s}-M_{f}\right)\right]\right)$ and $\left(H\left[-A_{f}+\dot{T}_{n}^{*}+\phi_{n}\left(A_{f}-A_{s}\right)\right]\right)$ specify the temperature at which the onset of the direct and inverse phase transformation occur, depending on the Martensite fraction in the region.

\section{Choice of $\phi_{\min }$ and $\phi_{\max }$ values:}

In order to consider the fact that the phase transformation inside a volume of NiTi material is not restricted to a single direction, but rather to multiple crystallographic orientations defined by the several martensite variants, the volume fraction of martensite in one region can reach a maximal value ' $\phi_{\max }$ ' greater than 1 . This means that the more favorable phase transformation orientation of one region can infringe on the less favorable orientation of the other regions [3]. This is similar to allowing multiple crystallographic orientations of the phase transformation in the same region. In this work, $\phi_{\max }$ is set equal to the number of regions ' $\mathrm{N}$ ', meaning that the martensite created in a region, can eventually occupy the entire volume of the wire. In the other hand, the minimum volume fraction of martensite ' $\phi_{\min }$ ' is set equal to zero. In fact, this 
parameter could be set to a value larger than zero to simulate some sort of irreversible phase transformation phenomena (such as blocked martensite) during cyclic loading [7].

Consequently, by imposing $\phi_{\min }=0$, it is assumed that the martensite created from austenite can be fully retransformed into austenite, which is the case when the material is stabilized by several training cycles prior to its characterization and working life [3].

\section{Thermomechanical coupling model:}

In order to evaluate the effective temperature of Eq.(6), a thermal model is coupled to the micromechanical formulation of the Likhachev model. Such addition permits to take into account the thermomechanical coupling.

In this work, the energy generated in the wire $\left(\mathrm{E}_{\mathrm{G}}\right)$ come from the latent heat of the phase transformation $\left(\mathrm{E}_{\mathrm{LH}}\right)$ which can be exothermic during the passage from austenite to martensite or endothermic during the reverse transformation.

$$
E_{G}=E_{L H}
$$

The latent heat contribution is simply the product of the volume fraction increment of martensite $\left(\Delta \Phi_{\mathrm{M}}\right)$, the latent heat per unit volume of phase transformation $\left(\mathrm{Q}_{0}\right)$ and the wire's volume $(\mathrm{V}=\mathrm{S} . \mathrm{L})$. This contribution has for expression :

$$
E_{L H}=Q_{0} S L \Delta \Phi_{M}
$$

Indeed, $\Delta \Phi_{M}$ has a direct effect on the nature of the latent heat contribution: if $\Delta \Phi_{M}>0$ then $\mathrm{E}_{\mathrm{LH}}>0$ (exothermic), else $\mathrm{E}_{\mathrm{LH}}<0$ (endothermic).

On the other hand, the energy generated in the wire will either be exchanged with the surrounding by convection $\left(\mathrm{E}_{\mathrm{C}}\right)$ or stored in the material $\left(\mathrm{E}_{\mathrm{S}}\right)$ as follows:

$$
E_{G}=E_{C}+E_{S}
$$

The first term of the addition in Eq.(10) is defined as the product of the wire's length (L), the perimeter of the cross-section $(\mathrm{P})$, and the convection coefficient $(\mathrm{H})$ :

$$
E_{C}=H L P\left(\bar{T}_{w}-\bar{T}_{a m b}\right) \Delta t
$$

where $\bar{T}_{w}=T_{w}+\frac{\Delta T_{w}}{2}$ and $\bar{T}_{a m b}=T_{a m b}+\frac{\Delta T_{a m b}}{2}$ are respectively the wire and ambient average temperatures during the time increment $\Delta \mathrm{t}$.

$E_{C}$ can either be positive or negative depending on whether the ambient temperature $\left(T_{a m b}\right)$ is lower or higher than the wire temperature $\left(\mathrm{T}_{\mathrm{w}}\right)$.

Moreover, the second term of the addition of Eq.(10), is given by the product of the specific heat per unit volume of the material $\left(\mathrm{C}_{\mathrm{P}}\right)$, the mass of the wire (given by the product of the 
density $(\rho)$, the length (L) and the cross-section (S)) and the wire temperature increment $\left(\Delta \mathrm{T}_{\mathrm{w}}\right)$ :

$$
E_{S}=C_{p} \rho L S \Delta T_{w}
$$

Substituting Equations (10)-(12) into Equation (9), $\Delta \mathrm{T}_{\mathrm{w}}$ can be determined as followed:

$$
\Delta T_{w}=\frac{Q_{0} S L \Delta \Phi_{M}-H L P\left(T_{w}-\bar{T}_{a m b}\right) \Delta t}{C_{p} \rho L S+\frac{H L P \Delta t}{2}}
$$

By considering the term $\frac{H L P \Delta t}{2} \ll<<C_{p} \rho L S$ and admitting that $\dot{T} \cong \frac{\Delta T}{\Delta T}=\frac{T_{t}-T_{t-\Delta t}}{\Delta t}$, the wire temperature rate can be written as follows:

$$
\dot{T}_{w}=\frac{Q_{0} S L \dot{\Phi}_{M}-H L P\left(T_{w}-\bar{T}_{a m b}\right)}{C_{P} \rho L S}
$$

In the case of wire, the circular section is a function of the diameter ' $\varnothing$ ' and has for expression: $S=\frac{\pi \varnothing^{2}}{4}$, and the wire temperature rate can be rewritten according to Eq.(15):

$$
\dot{T}_{w}=\frac{Q_{0} \dot{\Phi}_{M}-\frac{4}{\varnothing} H\left(T_{w}-\bar{T}_{a m b}\right)}{C_{p} \rho}
$$

\section{Experimental investigation and constants' determination for 1D simulation}

Ti-52 at $\% \mathrm{Ni}$ wires with pseudoelastic properties at room temperature were used in this investigation [8]. Nitinol wires were provided by Memry Corporation (Connecticut, USA) a SAES group getters company (Italy). These wires are dedicated to the application damping device (Fig.3). Several experimental investigations were realized (DSC analysis, tensile tests,..) in order to characterize the thermomechanical behavior of the material and to identify model parameters.

DSC analysis was performed on NiTi samples with a mass of $34.300 \mathrm{mg}$. These samples were first heated to $373 \mathrm{~K}$, cooled to $133 \mathrm{~K}$ and heated again to $373 \mathrm{~K}$, at heating/cooling rates of $5 \mathrm{~K} / \mathrm{min}$. With this procedure, one is able to estimate the corresponding transformation temperatures of the wire $\left(\mathrm{A}_{\mathrm{s}}, \mathrm{A}_{\mathrm{f}}, \mathrm{M}_{\mathrm{s}}, \mathrm{M}_{\mathrm{f}}\right)$. Those temperature values were used in the model (Fig.4). Indeed, the material is characterized by an austenite finish temperature $A_{f}=288 K$; therefore, it exhibits a fully austenitic structure at ambient temperature. With the same DSC measurements, the transformation latent heat $\left(\mathrm{Q}_{0}\right)$ and the specific heat $\left(\mathrm{C}_{\mathrm{p}}\right)$ were calculated. 
Tensile tests were carried out on a tensile testing machine with a capacity of $10 \mathrm{kN}$ at room temperature $(288 \mathrm{~K})$ to ensure that the material was in its pseudoelastic state. The wire samples have an initial length of $120 \mathrm{~mm}$ and a diameter of $2.46 \mathrm{~mm}$. An extensometer was used to provide the strain values with a reference length of $50 \mathrm{~mm}$. Two modes of control were tested. First, for the stress-controlled mode, four nominal stress rates were arbitrary used: 6.3 MPa.s ${ }^{-1}, 25.3 \mathrm{MPa}_{\mathrm{s}}{ }^{-1}, 126.3 \mathrm{MPa}_{\mathrm{s}} \mathrm{s}^{-1}$ and $315.6 \mathrm{MPa}^{-1}{ }^{-1}$ and the maximum tensile nominal stress, used in these tests, was set as $855 \mathrm{MPa}$. Second, for the strain-controlled mode, four nominal strain rates, i.e., $3.3 \times 10^{-4} \mathrm{~s}^{-1}, 1.3 \times 10^{-3} \mathrm{~s}^{-1}, 6.6 \times 10^{-3} \mathrm{~s}^{-1}$ and $1.6 \times 10^{-2} \mathrm{~s}^{-1}$ were prescribed. The maximum tensile nominal strain for each load case was set as $7 \%$. The range of input rates stress and strain rate were larger to cover more or less all operating conditions when NiTi wires are used as damping devices in civil engineering structures. From the resulting stress strain curves, elastic modulus for both austenite $\left(E_{A}\right)$ and martensite $\left(E_{M}\right)$ were measured. Values used for the numerical simulation are as follows: $E_{A}=60 \mathrm{GPa}$ and $\mathrm{E}_{\mathrm{M}}=29 \mathrm{GPa}$. These values are in agreement with the ranges of values in the medical literature. For example material property tables specify "elastic properties of NiTi" separately for austenite and martensite using relatively wide ranges as 41-75 GPa for the Young's modulus of the B2 austenite and 28-41 GPa for that of the B19' martensite. However and according to Petr Sittner et al., [10], Young's modulus of the B2 austenitic phase in NiTi was found to be $\mathrm{E} \sim 70 \mathrm{GPa}$ by all three experimental methods. If a smaller value is measured, then it is either due to the stress-induced B2-R transformation and/or R-phase reorientation taking place during the supposedly elastic loading of austenite, or due to internal intergranular stresses and residual martensite introduced into the wire microstructure.

As discussed in the second section, $\varepsilon_{\max }$ represent the maximum intrinsic transformation. In fact, [11] have carried out a crystallographic analysis on NiTi alloys and have determined the distortion tensor ' $\mathrm{D}_{\mathrm{ik}}$ ' which transforms the unit cell of austenite into the unit cell of martensite:

$$
D_{i k}=\left[\begin{array}{ccc}
-0.0337 & 0 & 0 \\
0 & 0.0763 & -0.0642 \\
0 & -0.0642 & -0.0418
\end{array}\right]
$$

After diagonalization of the tensor, the new form of ' $\mathrm{D}_{\mathrm{ik}}$ ' is as folows:

$$
D_{i k}=\left[\begin{array}{ccc}
-0.0337 & 0 & 0 \\
0 & 0.1045 & 0 \\
0 & 0 & -0.0699
\end{array}\right]
$$


The maximum principal value of this tensor gives a strain of $10.45 \%$ which corresponds to the maximum strain observed in a single crystal. Indeed, [5] have shown that this parameter is between 3 and $10.5 \%$. In this study, $\varepsilon_{\max }$ as well as ' $\beta$ ' is depending on the applied stress and strain rate and was determined for each case of loading after identification using SiDoLo. The number of regions in this study is set to $250(\mathrm{~N}=250) . \phi_{\min }$ and $\phi_{\max }$ are fixed to 0 and 250 , respectively.

Material constants used in the 1D simulation are summarized in Table 1.

\section{Results and discussion}

\subsection{Stress-controlled formulation}

\subsubsection{Case of low stress rate}

Fig.5. shows the numerical results of the 1D simulation carried out on NiTi wires under a stress-controlled formulation for a stress rate of $6.3 \mathrm{MPa}^{-1}{ }^{-1}$. The evolution of the imposed stress, wire temperature $\left(\mathrm{T}_{\mathrm{w}}\right)$, total strain $\left(\varepsilon_{\mathrm{tot}}\right)$, elastic $\left(\varepsilon_{\text {elas }}\right)$, phase transformation $\left(\varepsilon_{\mathrm{Tr}}\right)$ strains, the global proportion of martensite $\left(\Phi_{M}\right)$ versus time are given in Fig.5(a)-(e). The kinetic of phase transformation for region 1 and 250 is shown in Fig.5(f) and the resulting stress-strain curve is given in Fig.5.(g).

The simulation begins at room temperature $(288 \mathrm{~K})$ corresponding to a fully austenitic phase. In that state $(t<100 \mathrm{~s})$, the wire deforms elastically and the phase transformation strain as well as the global fraction of martensite are still equal to zero. Consequently, the austenite deforms elastically $(\mathrm{EA} \approx 60 \mathrm{GPa})$ and the deformation in the wire is homogenous $\left(\mathrm{OO}^{\prime}\right)$. When the stress is increased until reaching $600 \mathrm{MPa}$, the martensitic transformation occurs and is accompanied with the rise of the wire temperature (from 288 to $303.9 \mathrm{~K}$ ). This value of stress corresponds to the martensitic transformation yield stress $\left(\sigma_{\mathrm{Ms}}\right)$. It is well known that this passage from austenite to martensite is exothermic and is accompanied with heat exchange. In this state (100-115s), the proportion of martensite rises until reaching $100 \%$, therefore, the wire is fully transformed into martensite. Indeed, because of the different orientations of the regions, in some regions the phase transformations occurs (like region 1 in Fig.5(f-left) and others do not transform like region 250 (Fig.5(f-right) ). The evolution of the proportion of martensite in region 1 and 250 in function of the effective temperature is in respect with the phase transformation kinetic. 
The phase transformation strain reaches its maximum with a percentage greater than the elastic strain (5\% versus 3\%). The stress "plateau" in the stress-strain hysteresis loop (O'A) corresponds to the martensitic transformation. Between the $115^{\text {th }}$ and the $300^{\text {th }} \mathrm{s}$, the stress is released and the martensitic wire unloads elastically, $\Phi_{\mathrm{M}}$ as well as $\varepsilon_{\operatorname{Tr}}$ are stayed unchanged. However, the wire temperature decreases rapidly and reaches the ambient temperature (from 303.9 to $288 \mathrm{~K}$ ) and the martensite keeps its elasticity (AB). After 300s, the stress decreased slightly until reaching $190 \mathrm{MPa}$. The martensite transforms back into austenite. The reverse transformation is endothermic and so $T_{w}$ is decreased (until 281K). The reverse transformation is accompanied with a plateau in the mechanical response $\sigma-\varepsilon(\mathrm{BC})$ and it takes its end at 370 s. Finally, the austenitic wire unloads elastically with no residual strain is observed and consequently, the deformation is fully recovered (CO).

\subsubsection{Case of higher stress rate}

Fig.6. shows the numerical results of the 1D simulation carried out on NiTi wires under a stress-controlled formulation for a stress rate of $315.6 \mathrm{MPa} \cdot \mathrm{s}^{-1}$. The evolution of the imposed stress, wire temperature $\left(\mathrm{T}_{\mathrm{w}}\right)$, total strain $\left(\varepsilon_{\mathrm{tot}}\right)$, elastic $\left(\varepsilon_{\text {elas }}\right)$ and phase transformation $\left(\varepsilon_{\mathrm{Tr}}\right)$ strains and the global proportion of martensite $\left(\Phi_{\mathrm{M}}\right)$ in function of time are given in Fig.6(a)(e). The kinetic of phase transformation for region 1 and 250 is shown in Fig.6(f) and the resulting stress-strain curve is given in Fig.6(g).

For the case of higher stress rate, the period of the tensile test is about 40 times faster than the case of low stress rate (15s versus $600 \mathrm{~s})$. The evolutions of the different tested parameters are close to those obtained in the previous case. First, the nitinol wire deforms elastically with no phase transformation strain and the wire is still austenitic $\left(\mathrm{OO}^{\prime}\right)$. When the stress reaches $\sigma_{\mathrm{Ms}}$, which is close to $600 \mathrm{MPa}$, the austenite transform into martensite with $\Phi_{\mathrm{M}(\max )}=1$ (O'A). The two regions differ from each others with their orientations (angle $\theta$ ). Consequently, region 1 (with $\theta=0$ ) and region 250 (with $\theta=180^{\circ}$ ) are complementary and transform differently. In the first region the phase transformation occurs, however, the region 250 doesn't transform. Moreover, the temperature of the wire increases from the ambient to $317 \mathrm{~K}$. This value is higher than the temperature reached when the stress rate is low. This increase can be assumed to the high heating due to the thermo-mechanical coupling related to the presence of the R-phase [12] and also to localization effects. During the phase change, the temperature of the wire increases due to heat generation [13]. The stress plateau of the stressstrain curve corresponds to the martensitic transformation. Indeed, the slope of stress plateau (i.e., transformation hardening modulus) in the loading part increases monotonically with the 
stress rate. Thus, rate dependence seems to result from strong thermo-mechanical coupling, pseudoelasticity degeneration and temperature dependence [14]. After 5s, the stress is released and the martensite deforms elastically until 8s (AB). After this time, the stress remains decreasing and the reverse transformation begins. Such transformation is represented by the second stress plateau in the mechanical response (BC). The wire temperature decreases from 310 to $279 \mathrm{~K}$, at this temperature, the reverse transformation takes its end. Finally the wire is fully austenitic with any residual strain (CO). Consequently, as discussed preciously, the formulation of Likhachev model allows a good simulation of the pseudoelastic behavior of NiTi.

\section{Strain-controlled formulation}

\subsection{The followed procedure}

The stress-controlled formulation is not compatible with several Finite element (F.E) simulation codes here which require strain or displacement formulation. In order to adapt this formulation to a strain-controlled one in FORTRAN program and to be implemented after in a F.E software, a strain rate state must be imposed. The phase transformation strain rate was evaluated by Likhachev formulation and the elastic strain rate was calculated as the difference between the two strain rates as follows:

$$
\dot{\varepsilon}_{\text {elas }}=\dot{\varepsilon}_{\text {tot }}-\dot{\varepsilon}_{T r}
$$

By introducing the mixing rule with $\Phi_{M}$ as a weighting parameter, the resulting stress rate is given by the equation (17).

$$
\dot{\sigma}=\left(E_{M}-E_{A}\right) \dot{\Phi}_{M} \varepsilon_{\text {elas }}+\left(E_{A}\left(1-\Phi_{M}\right)+E_{M} \Phi_{M}\right) \dot{\varepsilon}_{\text {elas }}
$$

\subsection{Numerical results}

Fig.7 shows the results of the numerical simulation under strain-controlled formulation. The evolution of the imposed strain is given in Fig.7(a). The time history of $\sigma, \varepsilon_{\mathrm{Tr}}, \varepsilon_{\mathrm{elas}}, \mathrm{T}_{\mathrm{w}}$ and $\Phi_{M}$ are shown in Fig.7(b)-(e). The kinetic of phase transformation as well as the stressstrain curve are given in Fig.7(f,g).

During the rise of strain, the resulting stress increases rapidly until reaching a value of 520MPa. The wire deforms elastically $\left(\varepsilon_{\mathrm{Tr}}=0, \Phi_{\mathrm{M}}=0\right)$ and its temperature remains constant. 
The elastic deformation is about $1 \%$. After $80 \mathrm{~s}$, the stress continues to rise but with a slight slope until reaching a value of about $600 \mathrm{MPa}$. In this state, $\mathrm{T}_{\mathrm{w}}$ increases and the transformation from austenite to martensite occurs with $5 \%$ of $\varepsilon_{\mathrm{Tr}}$. The propotion of martensite in the regions rises and so the global fraction of martensite is accumulated untill reaching $100 \%$. Therefore, the wire is fully martensitic at $7 \%$ of total strain.

When the imposed strain decreases, the stress decreases too. Moreover, the elastic strain decreases and the phase transformation strain remains constant. Indeed, the martensitic wire deforms elastically for about $100 \mathrm{~s}$. After $600 \mathrm{~s}$, the $\mathrm{T}_{\mathrm{w}}$ continues to decrease as well as the strains. The reverse transformation occurs and the martensite transforms back to austenite and finally the nitinol wire recovers its pseudoelasticity with any residual strain. Such behavior is again obtained. So this adapted formulation is able to simulate the superelastic behavior of NiTi under a stress-controlled formulation as well as with a strain-controlled one.

\section{Stress/strain rate effect's simulations}

Stress-strain curves coming from experimental and numerical tensile tests for four stress rates 6.3MPa.s ${ }^{-1}$, 25.3 $\mathrm{MPa}^{-1}{ }^{-1}, 126.3 \mathrm{MPa}^{-1}{ }^{-1}$ and 315.6 MPa.s $\mathrm{M}^{-1}$ are shown in Fig.8.

As well as, Fig.9 shows the comparison between experimental and simulation results concerning the strain-controlled formulation for various strain rates $3.3 \times 10^{-4} \mathrm{~s}^{-1}, 1.3 \times 10^{-3} \mathrm{~s}^{-1}$, $6.6 \times 10^{-3} \mathrm{~s}^{-1}$ and $1.6 \times 10^{-2} \mathrm{~s}^{-1}$.

After parameters identification using SiDoLo (simulation and identification software propose by $\mathrm{P}$. Pilvin [6], $\varepsilon_{\max }$ and $\beta$ are determined and their evolution is strongly dependent on the imposed stress/strain rate. As noticed, the rise of strain rate is accompanied with the rise of the martensitic tranformation yield stress $\left(\sigma_{\mathrm{Ms}}\right)$. This rise can be assumed to the high heating due to the thermo-mechanical coupling related to the presence of the R-phase $[\mathbf{7 , 1 2}]$ and also to localization effects. Indeed, during phase transformation and because of the exothermic nature of the passage from austenite to martensite, the temperature of the alloy increases due to heat generation. So, the austenitic phase which is stable at high temperature becomes more stable and higher stress is required to drive the formation of martensitic during 
the direct transformation. In addition, during the reverse transformation, the temperature decreases making martensite more stable. Therefore, stress must be decreased further for the transformation from martensite back into austenite to continue. As a result, the slope of stress plateau in the loading part increases monotonically with the strain rate. Such evolution is well simulated by the model. It is worth to notice that there is a good agreement between experimental and numerical results for the two cases. The yield stress of the reverse transformation ' $\sigma_{\mathrm{As}}$ ' are well simulated especially when using the stress-controlled formulation. Consequently, the proposed model is able to reproduce the main experimental observations obtained under uniaxial tensile loading when a stress/strain rate is varied.

\section{Conclusions}

The pseudoelastic response of NiTi wires under various stress/strain rates was numerically simulated using a simple 1D thermomechanical model. The micromechanical formulation of Likhachev model is coupled to a thermal one resulting on the studied model. Such model is very attractive because it is based on a few number of material constants, which are detremined with simple experiments (DSC, tensile tests). Two types of formulations were tested: the stress-controlled and the adapted strain-controlled one. The following conclusions can be drawn:

(1) the stress-controlled formulation allows to simulate the mechanical response of NiTi wires under uniaxial tensile tests. The evolutions of the differents parameters like wire temperature, the resulting stress, the global proportion of matensite are well simulated;

(2) by adapting the stress-controlled formulation to a strain-controlled one, the hysteresis behavior is also well simulated and the different evolutions of parameters is quite good;

(3) the Likhachev formulation is able to take into account the numerical simulation under various stress/strain rates and the resulting stress-strain curves are close to the experimental ones. A good agreement is noted.

\section{References:}


[1] Brailovski, V, Prokoshkin S, Terriault P, Trochu F (eds) 2003. Shape Memory Alloys: Fundamentals, Modeling and Application, Éditions de l'École de technologie Supérieure, Montréal, Canada,

[2] Likhachev V (1995) Structure-Analitycal Theory of Martensitic Unelasticity. Journal de Physique IV, 05 (C8): C8-137-C8-142.

[3] Terriault P, Brailovski V (2011) Modeling of Shape Memory Alloy Actuators Using Likhachev's Formulation. Journal of Intelligent Material Systems and Structures 22: 353-368.

[4] Terriault P, Brailovski V (2013) Implementation of Likhachev's Model into a Finite Element Program. Materials Science Forum 738-739 : 160-164.

[5] Bhattacharya K, \& Kohn R.V (1995). Symmetry, texture and the recoverable strain of shape-memory polycrystals. Acta Metallurgica, 44(2), 529-542.

[6] Pilvin P, SiDoLo Version 2.5298, Notice d'utilisation, (2010)

[7] Paradis A, Terriault P, Brailovski V (2009) Modeling of residual strain accumulation of NiTi shape memory alloys under uniaxial cyclic loading, Computational Materials Science 47:373-383.

[8] Ammar O, Haddar N, Dieng L (2017) Experimental investigation of the pseudoelastic behaviour of NiTi wires under strain- and stress-controlled cyclic tensile loadings. Intermetallics 81: 52-61.

[9] Peigney E, Merliot E, Dieng L : Brevet amortisseur avec composant en alliage à mémoire de forme et limiteur de température: dispositif de maintien comprenant cet amortisseur. Laboratoire central des ponts et chaussées, juin 2011.

[10] Šittner P, Heller L, Pilch J, Curfs C, Alonso T, Favier D (2014) Young's modulus of austenite and martensite phases in superelastic NiTi wires. Journal of Materials Engineering Perform 23:2303-14. doi: http://dx.doi.org/10.1007/s11665-014-0976.

[11] Knowles K.M., Smith D.A. (1980) « The crystallography of the martensitic transformation in equiatomic Nickel-Titanium», Acta Metallurgica 29:101-110.

[12] Helbert G, Saint-Sulpice L, Arbab-Chirani S, Dieng L, Lecompte T, Calloch S and Pilvin P (2014) Experimental characterisation of three-phase NiTi wires under tension. Mechanics of Materials 79: 85-101. 
[13] Ortin J and Planes A (1989) Thermodynamics of thermoelastic martensitic transformations. Acta Metallurgica 37:1433-1441.

[14] Kan Q, Yub Ch, Kanga G, Lib J and Yan W (2016) Experimental observations on ratedependent cyclic deformation of super-elastic NiTi shape memory alloy. Mechanics of Materials 97:48-58. 


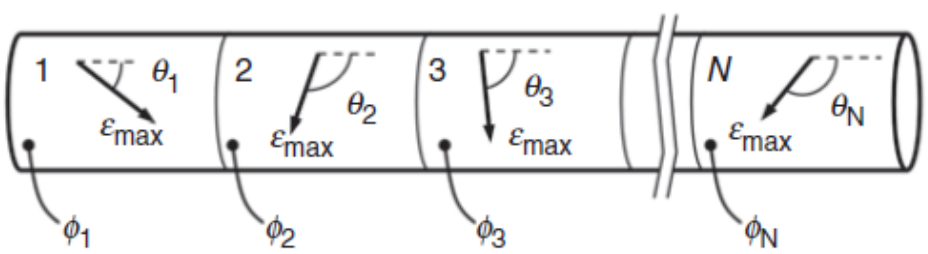

Fig. 1: Schematic representation of a SMA wire divided into a series of $N$ regions [3]. 


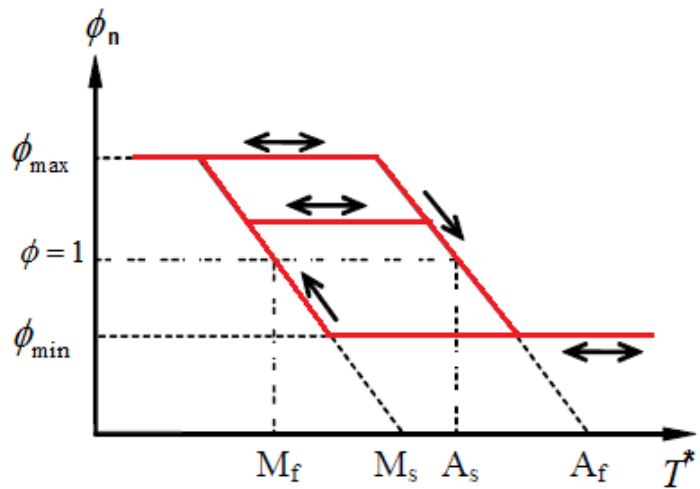

Fig. 2. Phase transformation kinetic rule [4]. 


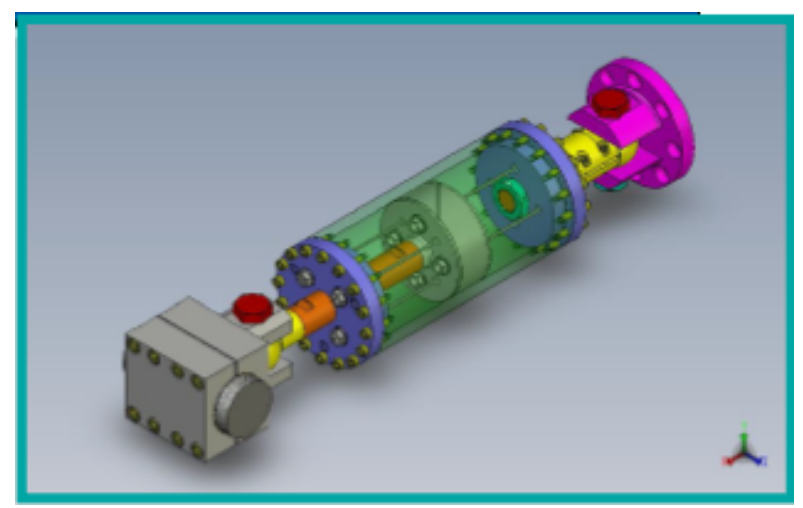

Fig.3. SMA damping; 4 wires // NiTi, 2 floors , $\varnothing=2,46 \mathrm{~mm}, L=200 \mathrm{~mm}$ Patent IFSTTAR (M.Peigney, E.Merliot, L.Dieng, 2010) [9]. 


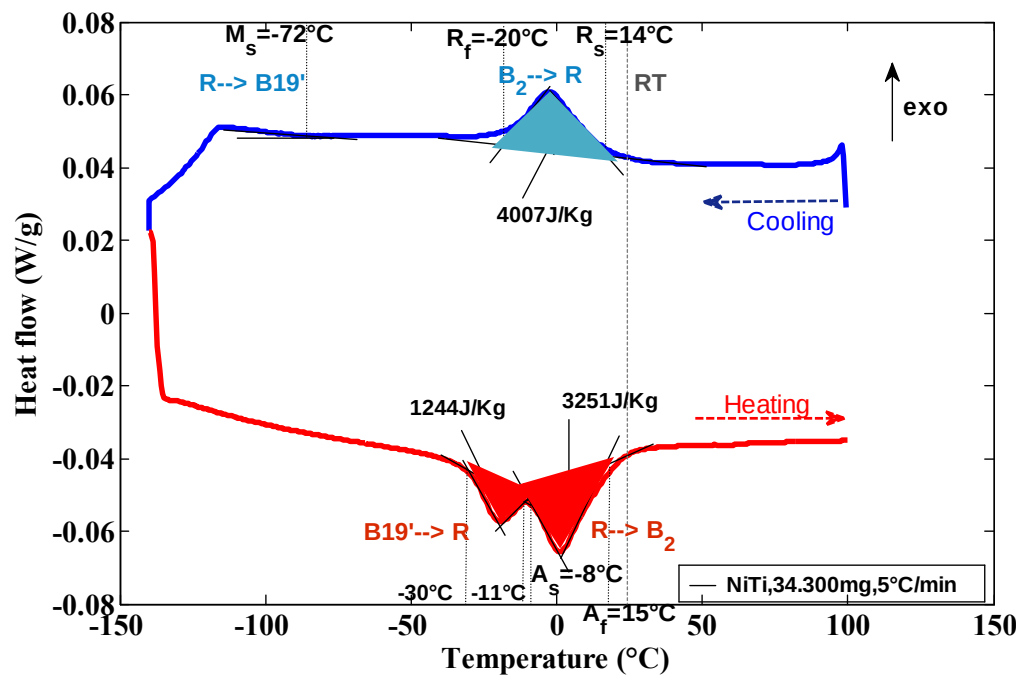

Fig.4. DSC thermograph for a Two-Stage transformation of a NiTi wire [8]. 

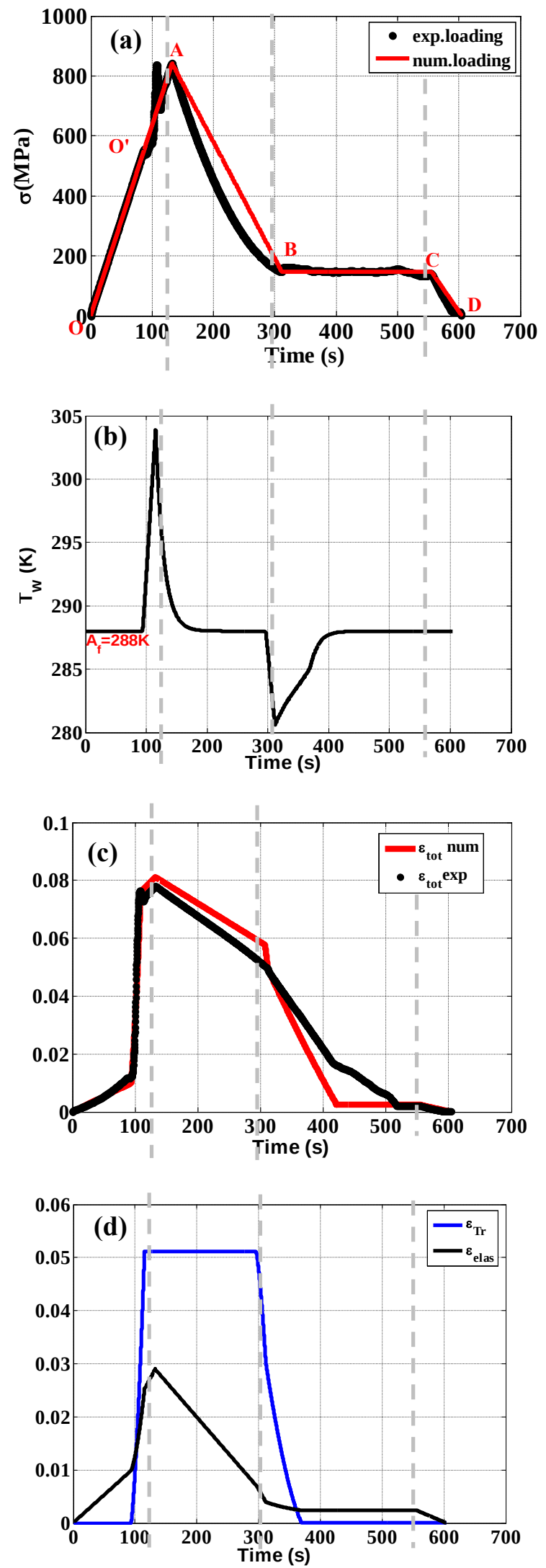

Fig.5 

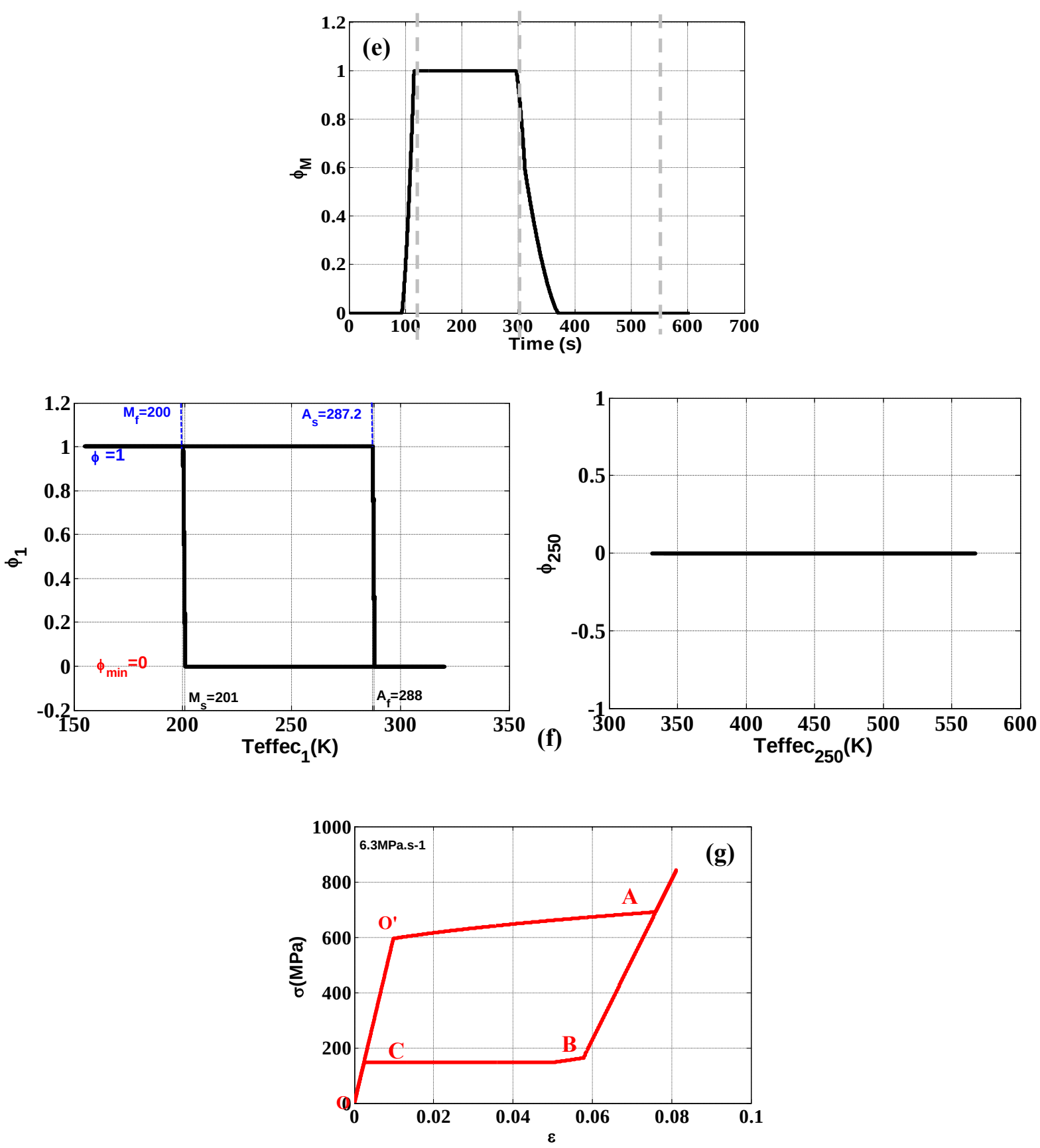

Fig.5 Numerical results of $1 D$ simulation under stress-controlled formulation of Likhachev

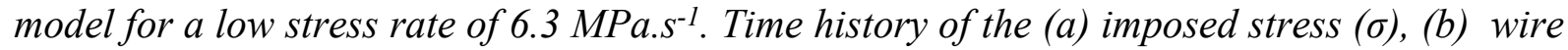
temperature $\left(T_{w}\right)$, (c) total strain $\left(\varepsilon_{\text {tot }}\right)$, (d) elastic $\left(\varepsilon_{\text {elas }}\right)$ and phase transformation $\left(\varepsilon_{T r}\right)$ strains, (e) global proportion of martensite $\left(\Phi_{M}\right)$, (f) kinetic of phase transformation and $(g)$ the numerical stress-strain curve. 

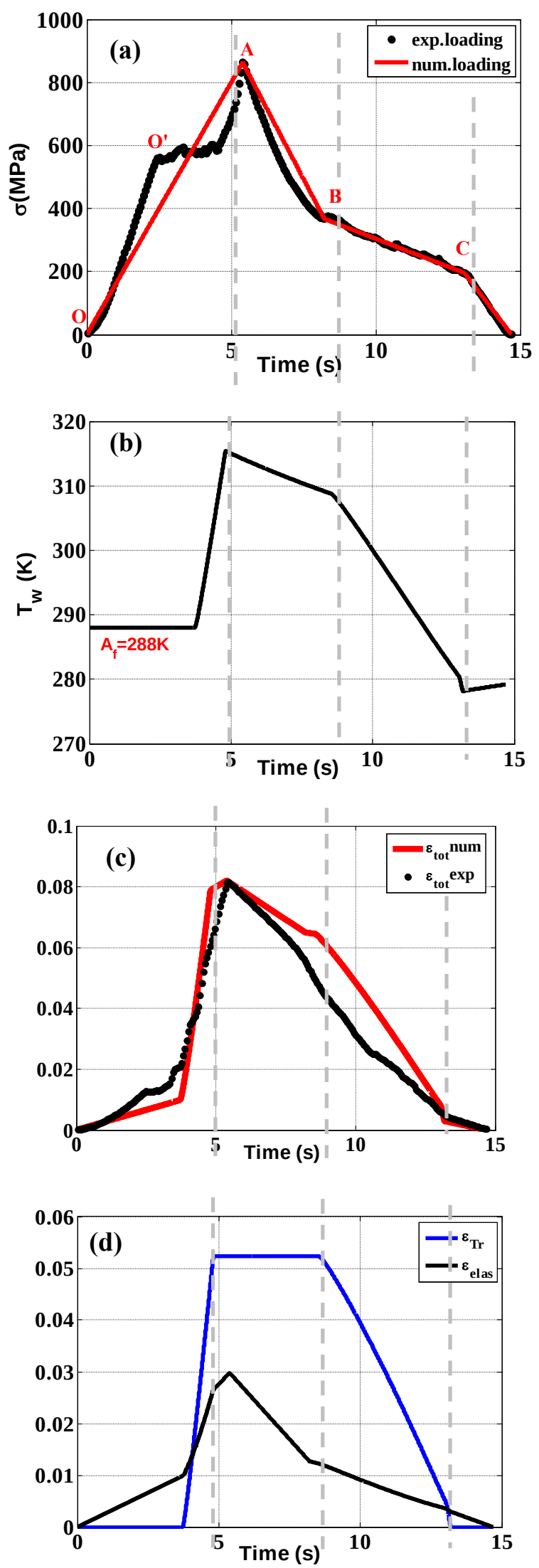

Fig.6. 

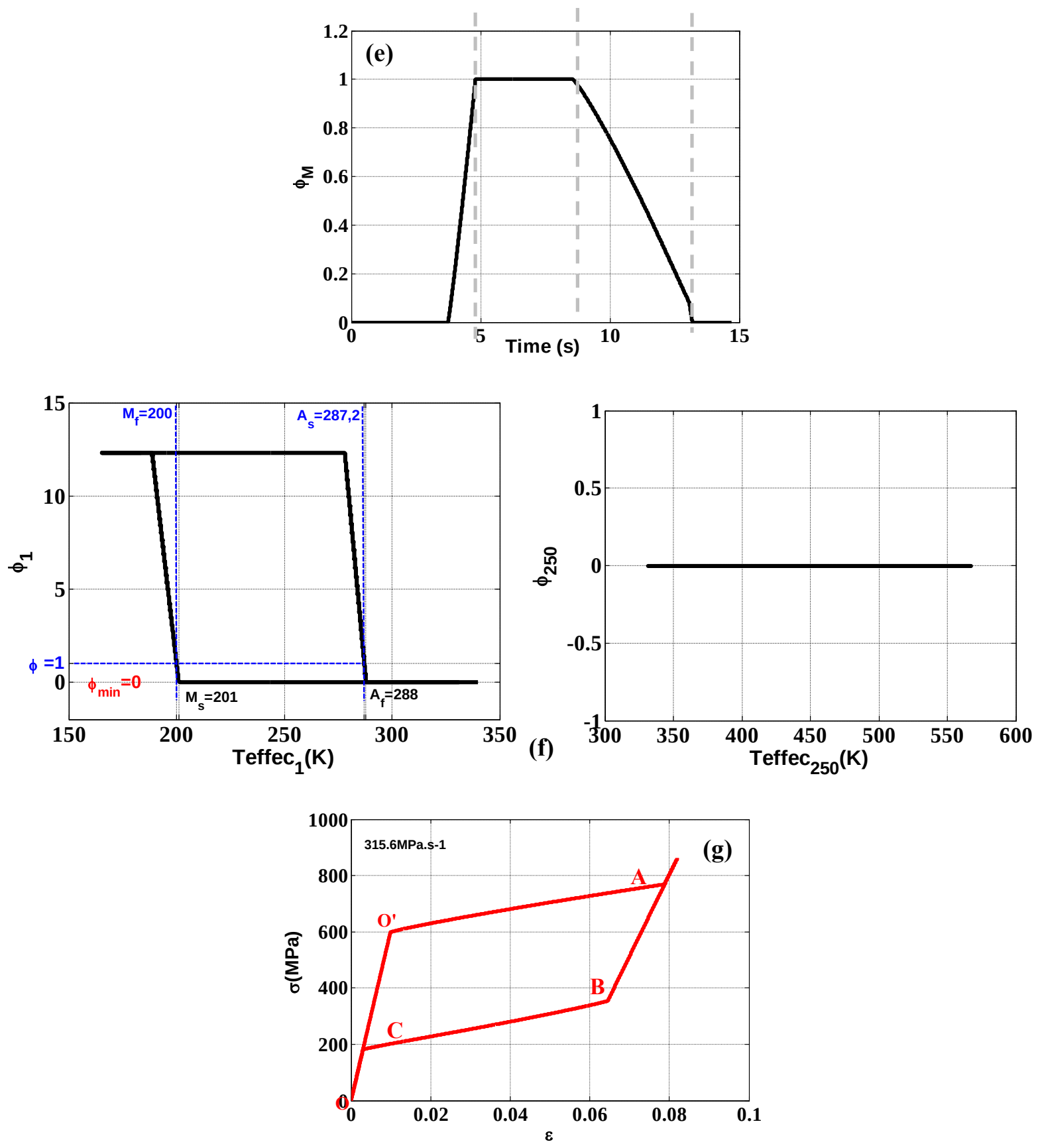

Fig.6. Numerical results of $1 D$ simulation under stress-controlled formulation of Likhachev model for a high stress rate of $315.6 \mathrm{MPa}_{\mathrm{s}} \mathrm{s}^{-1}$. Time history of the (a) imposed stress ( $\left.\sigma\right),(b)$ wire temperature $\left(T_{w}\right)$, (c) total strain $\left(\varepsilon_{\text {tot }}\right)$, (d) elastic $\left(\varepsilon_{\text {elas }}\right.$ and phase transformation $\left(\varepsilon_{T r}\right)$ strains, (e) global proportion of martensite $\left(\Phi_{M}\right)$, (f) kinetic of phase transformation and $(g)$ the numerical stress-strain curve. 

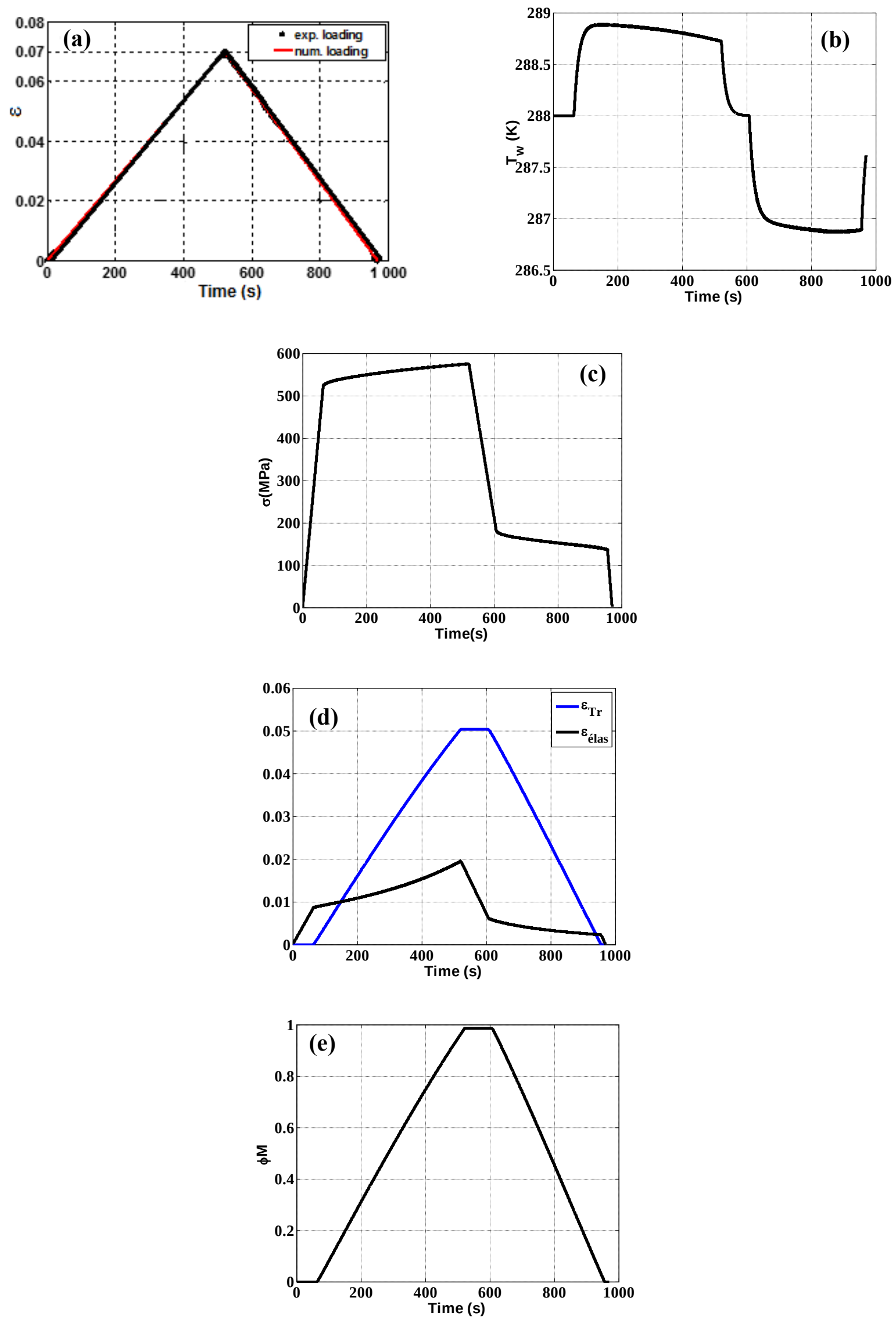

Fig.7. 

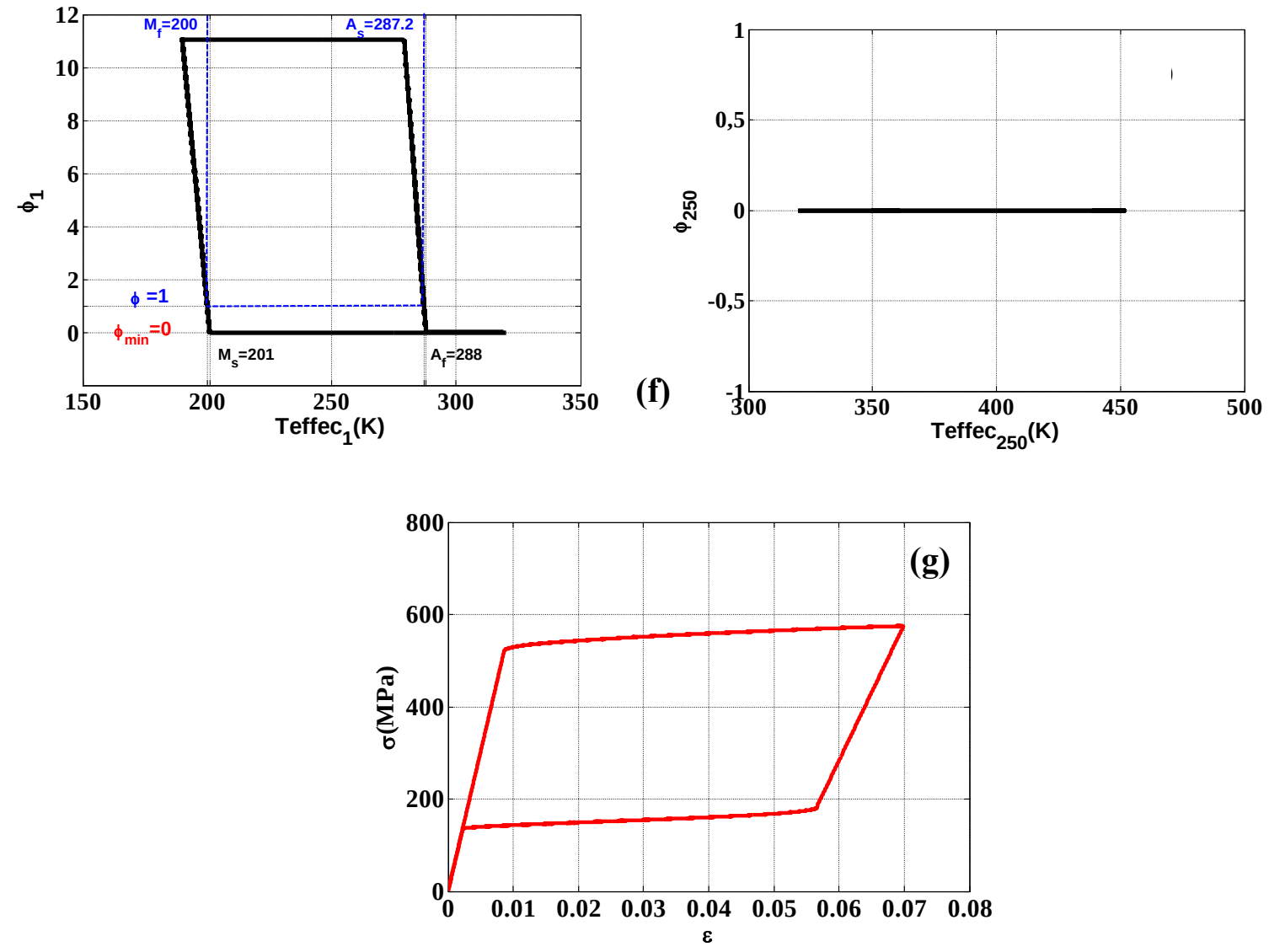

Fig.7. Numerical results of $1 D$ simulation under strain-controlled formulation of Likhachev model. Time history of the (a) imposed strain ( $\sigma)$, (b) resulting stress, (c) wire temperature $\left(T_{w}\right)$, (d) elastic ( $\varepsilon_{\text {elas }}$ and phase transformation $\left(\varepsilon_{T r}\right)$ strains, (e) global proportion of martensite $\left(\Phi_{M}\right)$, (f) kinetic of phase transformation and $(g)$ the numerical stress-strain curve 

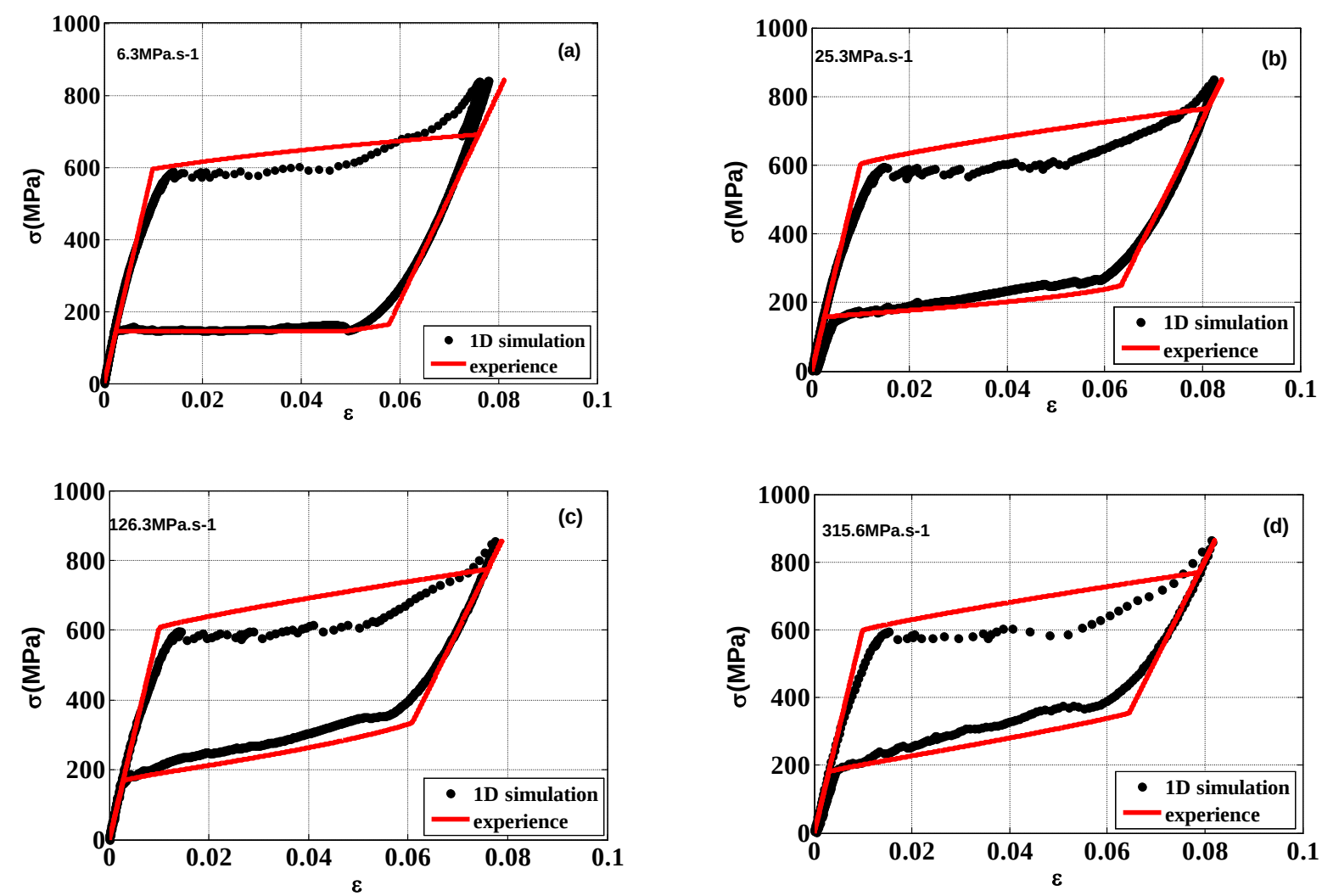

Fig.8. Comparison between experimental results and simulation concerning the Likhachev stress-controlled formulation at various stress rates: (a) $6.3 \mathrm{MPa} . \mathrm{s}^{-1}$, (b) $25.3 \mathrm{MPa}_{\mathrm{s}}^{-1}$, (c) 126.3 MPa.s s $^{-1}$ and (d) 315.6 MPa.s. ${ }^{-1}$. 

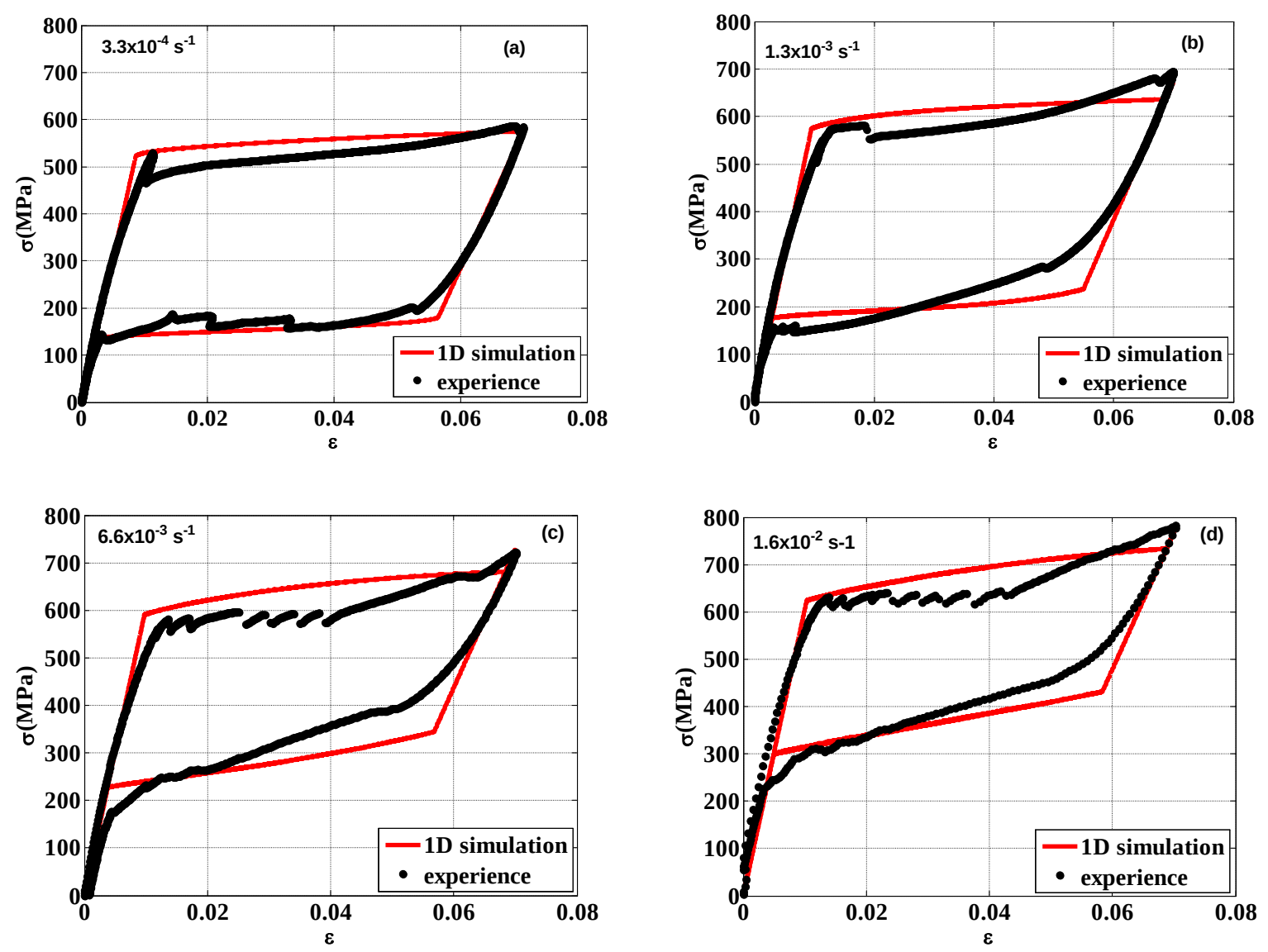

Fig.9. Comparison between experimental results and simulation concerning the Likhachev strain- controlled formulation at various strain rates: (a) $3.3 \times 10^{-4} \mathrm{~s}^{-1}$, (b) $1.3 \times 10^{-3} \mathrm{~s}^{-1}$, (c) $6.6 \times 10^{-3} \mathrm{~s}^{-1}$ and (d) $1.6 \times 10^{-2} \mathrm{~s}^{-1}$. 
Table1. Model parameters used for the $1 D$ simulation.

\begin{tabular}{lcc}
\hline \multicolumn{1}{c}{ Parameter (symbol) } & Value & Unit \\
\hline Length of wire $(\mathbf{L})$ & $120 \times 10^{-3}$ & $\mathrm{~m}$ \\
Section of wire (S) & $4.75 \times 10^{-6}$ & $\mathrm{~m}^{2}$ \\
Perimeter (P) & $15.45 \times 10^{-3}$ & $\mathrm{~m}$ \\
Diameter $(\square)$ & $2.46 \times 10^{-3}$ & $\mathrm{~m}$ \\
Young Modulus of Austenite $\left(\mathbf{E}_{\mathbf{A}}\right)$ & $60.4 \times 10^{9}$ & $\mathrm{~Pa}$ \\
Young Modulus of Martensite $\left(\mathbf{E}_{\mathbf{M}}\right)$ & $29 \times 10^{9}$ & $\mathrm{~Pa}$ \\
Austenite Start Temperature $\left(\mathbf{A}_{\mathbf{s}}\right)$ & 287.2 & $\mathrm{~K}$ \\
Austenite Finish Temperature $\left(\mathbf{A}_{\mathbf{f}}\right)$ & 288 & $\mathrm{~K}$ \\
Martensite Start Temperature $\left(\mathbf{M}_{\mathbf{s}}\right)$ & 201 & $\mathrm{~K}$ \\
Martensite Finish Temperature $\left(\mathbf{M}_{\mathbf{f}}\right)$ & 200 & $\mathrm{~K}$ \\
Transformation latent heat $\left(\mathbf{Q}_{\mathbf{0}}\right)$ & 100 & $\mathrm{MJ} / \mathrm{m}^{3}$ \\
Specific heat $(\mathbf{C p})$ & 545 & $\mathrm{~J} / \mathrm{Kg} \cdot \mathrm{K}$ \\
Convection coefficient $(\mathbf{H})$ & 80 & $\mathrm{~W} / \mathrm{m}^{2} . \mathrm{K}$ \\
Density $(\boldsymbol{\rho})$ & 6450 & $\mathrm{Kg} / \mathrm{m}^{3}$ \\
Room Temperature $\left(\mathbf{T}_{\text {amb }}\right)$ & 288 & $\mathrm{~K}$ \\
Number of regions $(\mathbf{N})$ & 250 & - \\
Maximum fraction of Martensite $\left(\phi_{\max }\right)$ & 250 & - \\
Minimum fraction of Martensite $\left(\phi_{\min }\right)$ & 0 & - \\
\hline
\end{tabular}


- The paper is not concurrently submitted for publication elsewhere

- The paper, in its entirety, in part, or in a modifies version, has not been published elsewhere

- The paper has not previously been submitted for possible publication elsewhere 